\title{
Medication-related anaphylaxis treated in hospital; agents implicated, patient outcomes and management lessons
}

\author{
Running title: Medication-related anaphylaxis \\ Linda V Graudins \\ Medication Safety Lead Pharmacist, Pharmacy Department, \\ Alfred Health, Melbourne, Australia \\ Jason Trubiano \\ Director of Antimicrobial Stewardship and Antibiotic Allergy, \\ Austin Health, Heidelberg, Victoria \\ Celia M Zubrinich \\ Consultant, Department Allergy, Immunology and Respiratory Medicine, \\ Alfred Health, Melbourne, Victoria \\ Ainslee S Elliott \\ B Sci student, \\ Monash University, Melbourne, Victoria
}

Ar Kar Aung

Consultant, Department of General Medicine and Infectious Diseases Alfred Health; and School of Public Health and Preventive Medicine, Monash University, Melbourne, Victoria Alfred Health, Melbourne, Australia

Correspondence:

Linda Graudins

Pharmacy Department

The Alfred

Commercial Road

Melbourne Vic 3004

AUSTRALIA

Tel: 61390763308

Email: I.graudins@alfred.org.au

Keywords:

Adverse Drug Reaction, anaphylaxis, medication safety, drug allergy, pharmcoepidemiology

This is the author manuscript accepted for publication and has undergone full peer review but has not been through the copyediting, typesetting, pagination and proofreading process, which may lead to differences between this version and the Version of Record. Please cite this article as doi: $10.1002 /$ pds.4587

This article is protected by copyright. All rights reserved. 


\section{Key points}

- Anaphylaxis is a rare, yet potentially life-threatening, immune-mediated hypersensitivity reaction

- Although medication-related anaphylaxis has low mortality, re-presentation increases morbidity and may be preventable in some cases

- Clinicians must provide clear information to patients after an initial reaction

- To improve patient safety adverse drug reaction management should include causality evaluation, referral systems and consistent documentation

Word Count: 1657

This project was presented as a poster at the Society of Hospital Pharmacists of Australia (SHPA) Medication Management Conference in Sydney, November 2017. The research has not been sponsored or funded.

This article is protected by copyright. All rights reserved. 


\begin{abstract}
AIM: On the background of increasing medication-related anaphylaxis rates in Australia, our aim was to determine epidemiology, outcomes, adverse drug reaction (ADR) reporting rates and accuracy of coding in patients treated after non-antimicrobial medication-related anaphylaxis in our hospital network.

METHODS: From January 2010 to December 2015 patients treated in our hospital network for medication-related anaphylaxis were identified using ICD-10 diagnosis code T88.6. Cases were also extracted from the hospital ADR database. Medical records were reviewed to ensure consistent diagnosis and to extract clinical, documentation and outcome data.

RESULTS: Of 1110 patients coded as T88.6, 177 (15.9\%) met the medication-related anaphylaxis definition. Eighty $(40.8 \%)$ had anaphylaxis due to non-antimicrobial agents. Thirteen of these $(16.3 \%)$ had a previous reaction to the same medication/group. In 51 (63.8\%) patients, anaphylaxis occurred during inpatient stay, with 31 reactions occurring during surgery. Eighty-five medications were implicated, most commonly neuromuscular blocking agents (NMBs) $(31,36.5 \%)$ and non-steroidal anti-inflammatory drugs (NSAIDs). No trends were noted over the six-year period and there was no anaphylaxis-related mortality. Fifty-three (66.3\%) patients were assessed in allergy clinics. One in ten cases did not have the reaction documented in the discharge summary. ADR reports were received for 38 patients (47.5\%).

CONCLUSION: Although acute patient outcomes were excellent, gaps in practice were noted regarding ADR coding accuracy and reporting rates. One in six patients had a prior hypersensitivity reaction to a similar medication, so we recommend accurate documentation, ADR review with allergy follow-up and patient held information to decrease re-exposure risk.
\end{abstract}

Words: 250 


\section{Introduction}

Both fatality rates and hospital admissions from medication-related anaphylaxis have been reported as increasing in Australia. ${ }^{1,2} \mathrm{~A}$ recent state government discussion paper called for mandatory reporting of anaphylaxis cases and identified the need for a system wide review of anaphylaxis management. ${ }^{3}$ As the current state of medication-induced anaphylaxis management in our hospital network was unknown, an analysis of patients with medicationrelated anaphylaxis over a six-year period was undertaken to determine; epidemiology, accuracy of coding, reporting rates of medication-related anaphylaxis and patient outcomes. As a concurrent study describing antimicrobial anaphylaxis ${ }^{4}$ is being conducted to determine the clinical impacts of immediate antibiotic hypersensitivity, this report is an analysis of anaphylaxis cases not related to antimicrobial agents.

\section{Setting}

The study cohort was taken from inpatient admissions and ED presentations at a universityaffiliated tertiary metropolitan 800-bed hospital network with state-wide specialty referral services. Reporting of adverse drug reactions (ADR) is actively encouraged within the hospital network, with pharmacists supplying $85 \%$ of the voluntary ADR reports. ${ }^{5}$ For over ten years, a multidisciplinary ADR Review Committee (ADRRC) has met every two weeks to prospectively review ADRs reported, determine causality and make recommendations. ${ }^{6}$ For reported ADRs, patients are provided with written information regarding the nature of reaction, recommendations and, where indicated, are referred for allergy clinic review.

\section{Methods}

Patients diagnosed with anaphylaxis to medications over a six-year period from January 2010 to December 2015 were retrospectively identified using i) the International Classification of Diseases, Tenth Edition (ICD-10) diagnosis code T88.6 (Anaphylactic reaction due to adverse effect of correct drug or medicament properly administered) as an admitting diagnosis and ii) the ADRRC database. Patients were considered to have had medicationrelated anaphylaxis if the diagnosis was stated in the medical record. Where a definitive clinician diagnosis or diagnosis was unclear, a retrospective classification was made according to national guidelines, i.e. if the patient had a record of an acute onset hypersensitivity reaction after medication ingestion, with typical skin features (urticarial rash or erythema/flushing, and/or angioedema), plus involvement of respiratory and/or cardiovascular and/or persistent severe gastrointestinal symptoms, or any acute onset of hypotension or bronchospasm or upper airway obstruction. ${ }^{7,8}$ All patients considered to have anaphylaxis, as defined above, were included in this study, regardless of the underlying immunologic mechanisms.

To determine whether the coding for medication-related anaphylaxis was accurate, each patient's scanned discharge summary and/or ADR report and allergy follow-up, where available, was reviewed for diagnosis of an anaphylactic reaction. Where causative agent was unclear or diagnosis not documented, the actual description of the reaction was reviewed. Adjudication was made by panel discussion (LG, AKA, CZ). To enable an overall 
incidence trends over time, the total of antimicrobial plus non-antimicrobial cases treated at our hospital network per 1000 bed days was graphed using Excel $\odot$ and calculated using linear regression analysis. Further data was collected for anaphylactic reactions caused by non-antimicrobial agents; patient demographics, allergy history, suspected allergen/s, serum tryptase (if available), treatment, immediate patient outcome and allergy clinic referral. ADR history including allergies, was determined from patient medical records, including the pharmacist medication reconciliation form, completed with the patient and /or carer on each admission. Prior ADRs were categorized as 'allergic', if 'anaphylaxis', itch, 'rash' was documented. Documentation of allergy referral was noted from the scanned discharge summary and/or ADR report, if available. Institutional Ethics Board approved this project as a low risk study (Approval: 596/16).

\section{Results}

\section{Reaction characteristics}

Of 1110 patients coded as T88.6 over the six-year study period, only 177 (15.9\%) patients were determined to have had medication-related anaphylaxis. The remainder were food, insect bite or environmental triggers, mis-coded as T88.6. In these 177 patients with medication-related anaphylaxis, 97 (52.7\%) involved antimicrobial agents. In the 80 cases of non-antimicrobial anaphylaxis, 85 medications were implicated. Neuromuscular blocking agents (NMBs) were most commonly implicated $(31,36.5 \%)$ followed by non-steroidal antiinflammatory agents (NSAIDs) (22, $27.5 \%$ ) (Table 1).

\section{Demographics [Table 2]}

In the 80 (43.4\%) patients treated for anaphylaxis to medications other than antimicrobials, $48(60 \%)$ were male with a median age 52 [IQR 35-66] years. Of these, $42(52.5 \%)$ patients reported a prior ADR of which 32 were an allergic-type reaction. Twelve $(15.0 \%)$ of these patients reported previously having an allergic reaction, ranging from rash to documented anaphylaxis (9) to the same medication/medication category.

\section{Management (Table 3)}

Fifty reactions (62.5\% of the total) occurred in inpatients, of which 31 (62.0\%) occurred during surgery and patients were transferred for on-going treatment in the intensive care unit. Two of these patients had previous reactions to NMBs. Thirty-six (45.0\%) patients were managed solely in the Emergency Department (25 from the community, 10 transferred from within the hospital and 1 patient from another hospital), without further hospitalization.

Glucocorticoids were administered in $71(88.8 \%)$ and anti-histamines in 56 (70.0\%) patients. Adrenaline was administered in 67 (83.8\%) patients; 41 by intramuscular (im) route, 54 by intravenous (iv) route and six by nebuliser. Seven patients were administered adrenaline by multiple routes. Metaraminol was administered in three patients not administered adrenaline. Of the eighty patients, 66 (82.5\%) had 133 tryptase levels taken and 42 patients had two or more levels. Levels for 32 (48.5\%) patients were elevated.

\section{Documentation and Outcomes}

No significant trend was noted in the incidence of all medication-related anaphylaxis cases treated at our hospital network over the study period [Slope: $0.001295 \pm 0.006509, \mathrm{R}$ - 
square: $0.009796, \mathrm{P}$-value: 0.85 (Figure 1)]. In the non-antimicrobial anaphylaxis cohort, there was no mortality during the index admission or presentation. Forty-two (52.5\%) patients were referred for allergy assessment. With regards to the most commonly implicated medications, 23or the 31 (67.7\%) patients with NMB-related reactions and four of the $22(19.0 \%)$ patients with NSAID-related anaphylaxis were referred for allergist review. Seventy-one patients $(91.3 \%)$ had the reaction documented in the discharge summary. An ADR report was received for 38 (47.5\%) of the study cohort.

\section{Discussion}

Anaphylaxis from non-antimicrobial medications in the hospital setting occurred in inpatients, more often than via presentation to the ED alone, with neuromuscular blocking agents being most commonly implicated. ${ }^{9,10}$ Studies reviewing the epidemiology of

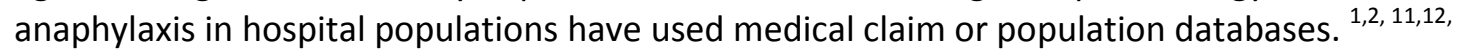
All conclude that medication-related anaphylaxis fatalities are rare, but increasing rate of presentations are of concern. A meta-analysis of all ADR s following emergency visits or hospital admissions found ADRs are a significant cause of morbidity and about half of all ADRs may be prevented. ${ }^{13}$ The risk factors of preventable ADRs are largely unknown, but may include increasing age, co-morbidity and multiple medications. Having a known previous reaction to any drug is not a proven risk for subsequent reactions. ${ }^{9,14}$ However, our finding that one in six patients in our study cohort had a prior allergic reaction to the same class or structurally similar medication, may indicate that a prior allergic drug reaction may pre-dispose to anaphylaxis. This requires further study to determine if subsequent presentations are potentially preventable.

The reported incidence of peri-operative anaphylaxis ranges from 1 in 3,500 to 1 in 13,000 cases ${ }^{15,16}$ The use of multiple medications during the operative period complicates causality determination. In many cases, the initial suspected agent(s) may later be deemed incorrect after allergy clinic assessment. ${ }^{17}$ Like previous studies, we found that NMBs are the most common agents implicated in peri-operative reactions. ${ }^{11}$

Half of the non-antimicrobial cohort was referred for an allergy review, a higher percentage than the $10 \%$ found in a study of patients with delayed type severe cutaneous ADRs in the same hospital network, indicating clinicians are more aware of allergy testing for anaphylaxis compared to delayed type reactions, which is limited by availability of resources for such testing. ${ }^{19}$ Allergist review may confirm the allergen implicated and lead to further testing to clarify which medications the patient may tolerate. ${ }^{20,21}$

There was variability in management of anaphylaxis. In contrast to the Banerji study ${ }^{12}$, where only $8 \%$ patients received adrenaline, adrenaline was administered in most of our patients, along with antihistamines and corticosteroids. Serum tryptase was measured in over $80 \%$ patients, and two-thirds had two or more levels taken, indicating the utility of this indicator for anaphylaxis, in addition to diagnosis on clinical features.

This was a retrospective observational study with known limitations. The study was undertaken within one hospital network; hence the sample may not be representative. However, the methodology is generalizable. Using the ICD system for clinical outcomes 
research has limitations and is dependent on the accuracy of the clinical coders. ${ }^{2,22} \mathrm{~A}$ large percentage of cases was mis-coded and if used as the sole source of data, would lead to over-estimating case numbers. On the other hand, voluntary ADR reporting underestimates the true number of cases. We used both sources, along with a detailed review of individual cases, to enhance the accuracy of our data. An unknown number of anaphylactic reactions are treated solely in the community and this was not captured by our data. We relied on documentation of patient records to determine ADR history and anaphylaxis diagnosis. This is a limitation to the study, however, this reflects clinical practice. ADR history is rarely verified on admission and not all cases are verified by an allergist. We support education and resources to ensure improvements in documentation and investigation of allergy-related ADRs.

Despite anaphylaxis being a life-threatening condition, less than half of the reactions were reported to the campus ADRRC and reactions were not always documented in the discharge summary. To optimize patient care, reporting to our ADRRC ensures evaluation, recommendations and referral. After an anaphylactic reaction, patients and/or carers must be informed about specific implicated agent(s), with recommendations for future medication use, to both prevent incorrect 'labelling' and more importantly, prevent reexposure to the offending agent(s). ${ }^{7,23}$ Written information, alert cards and alert bracelets, should be provided. Patient held electronic medical record has been introduced in Australia, with low initial uptake. ${ }^{24}$ As more information is uploaded into this system and use is mandated, accuracy of allergy information will be essential, to ensure the usefulness of this national initiative in decreasing risk of medication-related allergy recurrence.

\section{Conclusion}

There was no trend detected in medication-related anaphylaxis cases treated at our health care network over the six-year study period and zero mortality after the event in the nonantimicrobial sub-group. We found that cases were over-represented using ICD10 coding, yet under-reported via voluntary ADR reporting systems. Analysis of the non-antimicrobialinduced anaphylaxis cohort highlighted NMBs and NSAIDs to be the most commonly implicated medications. As part of ADR management, we recommend a consistent approach to ADR review by a dedicated hospital team to enable more accurate documentation and subsequent coding. One in six patients presenting with acute anaphylaxis had a prior reaction to the same or similar medication. Written recommendations for each patient with an allergist referral, where indicated, are recommended to decrease the risk of re-exposure and patient harm.

Acknowledgment: Dr. Maitri Munsif for initial data collation 


\section{References}

1. Liew WK; Williamson E; Tang ML. Anaphylaxis fatalities and admissions in Australia. J Allergy Clin Immunol 2009; 123:434-42

2. Mullins RJ; Wainstein BK; Barnes, EH; Liew WK; Campbell DE. Increases in anaphylaxis fatalities in Australia from 1997 to 2013. Clin Experiment Allergy 2016; 46: 1099-1110.

3. Safer Care Victoria [ homepage on the intranet] Mandatory reporting of anaphylaxis: Discussion paper. Victorian State Government. [Accessed May 2018]. Available from URL: $\quad$ https://www2.health.vic.gov.au/hospitals-and-health-services/safer-carevictoria/safer-care-publications/mandatory-reporting-anaphylaxis-discussion-paperjune-2017.

4. Hall V; Aung AK; Wong M; Munsif M; Booth J; Graudins LV; Johnson DF; Trubiano JA. Antimicrobial prophylaxis: The changing face of antimicrobial allergy. [Abstract 72] Australian Society Infectious Diseases. [homepage on the intranet] ASID Annual Scientific Meeting. [April 2017] Available from URL:

https://www.asid.net.au/documents/item/1335

5. Aung AK, Tang MJ, Adler NR et al. Adverse drug reactions reported by healthcare professionals: reaction characteristics and time to reporting. J Clin Pharmacol 2018; 0: 18.

6. Graudins LV; Hopper I; Treseder RJ; Lord JAV; Dooley MJ. Adverse Drug Reactions during Hospital Stay: Evaluation of a model for informing patients. J Pharm Prac Res 2012; 42: 95-99.

7. Australasian Society of Clinical Immunology and Allergy (ASCIA) [homepage on the intranet] Anaphylaxis Resources. [ Updated June 2017. Accessed May 2018]. Available from URL: https://allergy.org.au/health-professionals/anaphylaxis-resources

8. Lieberman P; Nicklas RA; Oppenheimer J; et al. The diagnosis and management of anaphylaxis practice parameter: 2010 Update. J Allergy Clin Immunol 2010; 126; 477522.

9. Brown SGA; Mullins RJ; Gold MS. Anaphylaxis: diagnosis and management. Med J Aust 2006; 185: 283-289.

10. Turner PJ, Jerschow E, Thisanayagan U, Lin R, Campbell DE, Boyle R. Fatal anaphylaxis: mortality rate and risk factors. Allergy Clin Immunol Pract 2017; 5:1169-78.

11. Thong BY-H, Tan T-C. Epidemiology and risk factors for drug allergy. British Journal of Clinical Pharmacology. 2011;71(5):684-700. doi:10.1111/j.1365-2125.2010.03774.x.

This article is protected by copyright. All rights reserved. 
12. Banerji A, Rudders S, Clark S, wei W, Long A, Camargo CA. Retrospective study of druginduced anaphylaxis treated in the emergency department or hospital: patient characteristics, management, and 1-year follow-up. J Allergy Clin Immunol Pract 2014 2(1):46-51.

13. Hakkarainen KM, Hedna K, Petzold M, Hagg S (2012) Percentage of Patients with Preventable Adverse Drug Reactions and Preventability of Adverse Drug Reactions - A Meta-Analysis. PLoS ONE 7(3): e33236. doi:10.1371/journal.pone.0033236

14. Pumphrey R. Anaphylaxis: can we tell who is at risk of a fatal reaction? Curr Opin Allergy Clin Immunol 2004; 4(4):285-90.

15. Nel L; Eren E. Peri-operative anaphylaxis. Br J Clin Pharmacol 2011; 71:647-58.

16. Hepner DL; Castells MC. Anaphylaxis During the Perioperative Period. Anesth Analg 2003; 97:1381-95.

17. Spoerl D; Nigolian H; Czarnetzki C.; Harr T. Reclassifying Anaphylaxis to Neuromuscular Blocking Agents Based on the Presumed Patho-Mechanism: IgE-Mediated, Pharmacological Adverse Reaction or "Innate Hypersensitivity"? Int. J. Mol Sci 2017; 18: 1223.

18. Kroigaard M. Allergic reactions in anaesthesia: are suspected causes confirmed on subsequent testing? Br J Anaesthesia 2005; 95: 468-471.

19. Graudins LV; Ly J; Trubiano J; Aung, AK. More than skin deep. Ten-year follow-up of delayed cutaneous adverse drug reactions (CADR). Br J Clin Pharmacol 2016; 82: 10401047.

20. Kowalski ML; Asero R; Bavbek S; Blanca $\quad \mathrm{M}$; Blanca-Lopez $\quad \mathrm{N}$; Bochenek $\mathrm{G}$; et al. Classification and practical approach to the diagnosis and management of hypersensitivity to nonsteroidal anti-inflammatory drugs. Allergy 2013; 68: 1219-1232.

21. Renaudin JM; Beaudouin E; Ponvert C; Demoly P; Moneret-Vautrin DA. Severe druginduced anaphylaxis: analysis of 333 cases recorded by the Allergy Vigilance Network from 2002 to 2010. Allergy 2013; 68: 929-937.

22. Hohl CM; Karpov A; Reddekopp L; Stausberg J. ICD-10 codes used to identify adverse drug events in administrative data: a systematic review J Am Med Inform Assoc 2014; 21:547-55

23. Victorian Institute of Forensic Medicine Clinical Communique 2017; 4 (3). Available at URL: http://www.vifmcommuniques.org/?p=5120. Accessed May 2018.

24. Commonwealth of Australia 2017. Digital Health Agency. My Health Record Statistics. Available from URL: https://www.myhealthrecord.gov.au/sites/g/files/net4206/f/my_health_record_dashbo ard_-_29_april_2018.pdf?v=1525406770 ( Accessed May 2018) 


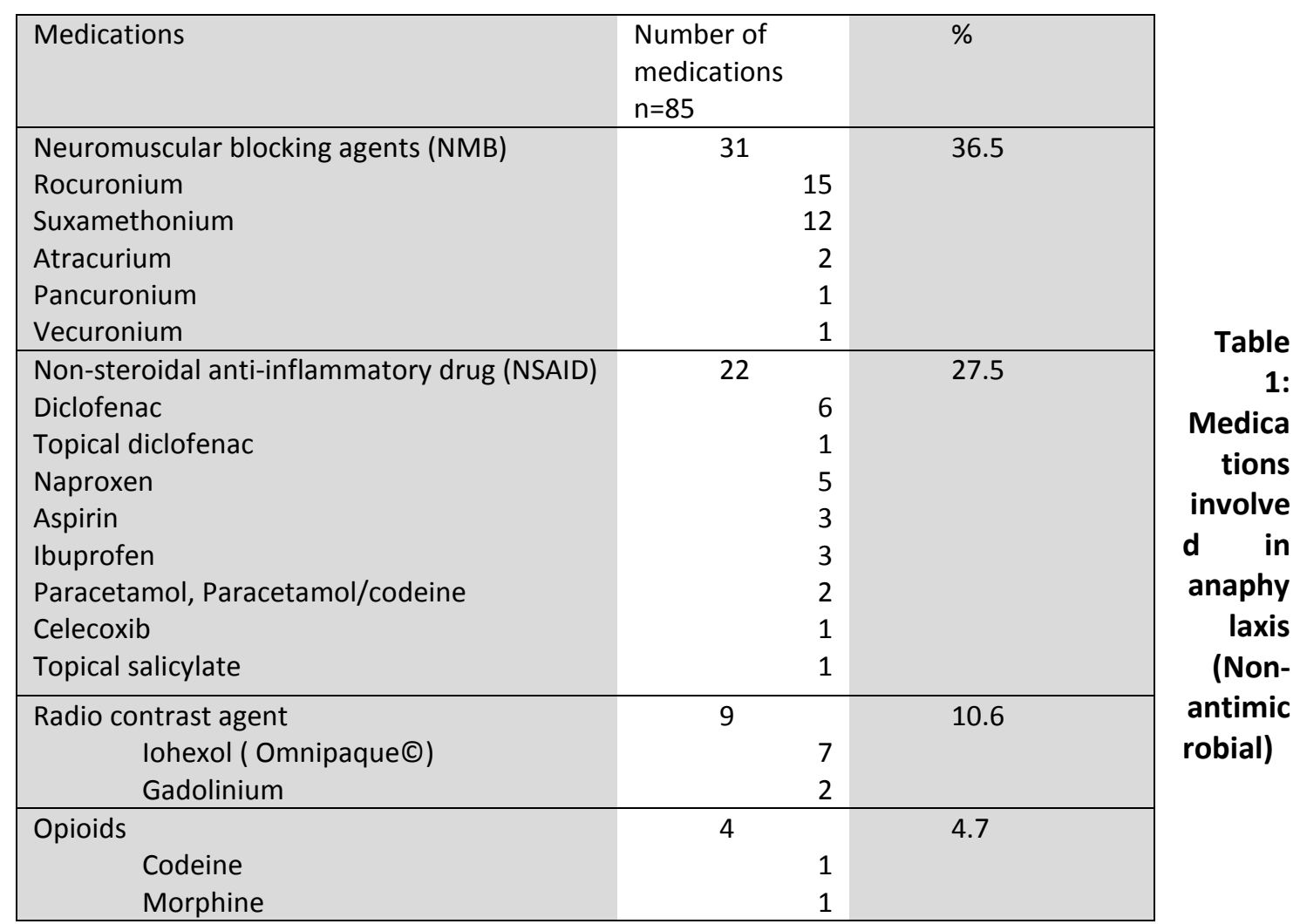




\begin{tabular}{|lll|}
\hline \multicolumn{1}{|c|}{$\begin{array}{l}\text { Oxycodone } \\
\text { Pethidine }\end{array}$} & $\begin{array}{l}1 \\
1\end{array}$ \\
\hline Protamine & 3 & 3.5 \\
\hline Taxol, Oxaliplatin & 2 & 2.4 \\
\hline Iron Polymaltose & 2 & 2.4 \\
\hline Ticagrelor, prasugrel $^{\ddagger}$ & 2 & 2.4 \\
\hline Other $^{\ddagger}$ & 10 & 12.5 \\
\hline
\end{tabular}

† Peri-operative- neuromuscular blocking agent causality probable or definite (re-challenge, skin testing), concurrent administration with propofol, opioids, cephazolin ‡ Other: Anti-thymocyte globulin, atorvastatin, dihydroergotamine, gelatin succinylated, methylene blue, mifepristone, multivitamin, $\mathrm{N}$-acetylcysteine, triamcinolone injection, pantoprazole.

This article is protected by copyright. All rights reserved. 


\begin{tabular}{|l|l|l|}
\hline Variable & $\mathbf{n = 8 0}$ & $\mathbf{\%}$ \\
\hline Male & 48 & 60.0 \\
\hline Age median (IQR) years & $52(35-66)$ & \\
\hline Prior reaction to any medication & 42 & 52.5 \\
Allergic-type reaction & 32 & \\
Non-allergic reaction & 6 & \\
Unable to determine & 4 & \\
Prior allergic reaction to a similar medication/ class & 12 & 15.0 \\
Non-steroidal anti-inflammatory (NSAID) & 6 & \\
Neuromuscular blocking agent & 2 & \\
Other (gadolinium, oxaliplatin, multivitamin, & 4 & \\
triamcinolone) & & \\
\hline
\end{tabular}

Table 2:

Patient

demograp

hics

\begin{tabular}{|c|c|c|}
\hline Variable & $n=80$ & $\%$ \\
\hline $\begin{array}{l}\text { Place of anaphylaxis onset } \\
\text { In hospital } \\
\text { Operating suite } \\
\text { Ward } \\
\text { Radiology } \\
\text { Intensive Care Unit } \\
\text { Emergency Department } \\
\text { Outside of hospital } \\
\text { Community } \\
\text { Transfer from another hospital } \\
\text { Oncology outpatient }\end{array}$ & $\begin{array}{r}31 \\
7 \\
6 \\
4 \\
2 \\
\\
27 \\
2 \\
1\end{array}$ & $\begin{array}{c}2.5 \\
1.4 \\
33.6\end{array}$ \\
\hline $\begin{array}{l}\text { Location of on-going treatment } \\
\text { Emergency Department } \\
\text { ICU } \\
\text { Ward }\end{array}$ & $\begin{array}{r}36 \\
37 \\
7\end{array}$ & $\begin{array}{l}45.0 \\
46.2 \\
10.0\end{array}$ \\
\hline $\begin{array}{l}\text { Tryptase level taken } \\
\text { Elevated (above } 15.0 \text { microg/ mL) }\end{array}$ & 66 & 82.5 \\
\hline
\end{tabular}

Table 3:

Reaction

characteris

tics

This article is protected by copyright. All rights reserved. 
This article is protected by copyright. All rights reserved. 
Fig 1: Total medications-related (antimicrobial and non-antimicrobial) anaphylaxis cases per 1000 occupied beddays: January 2010 to December 2015

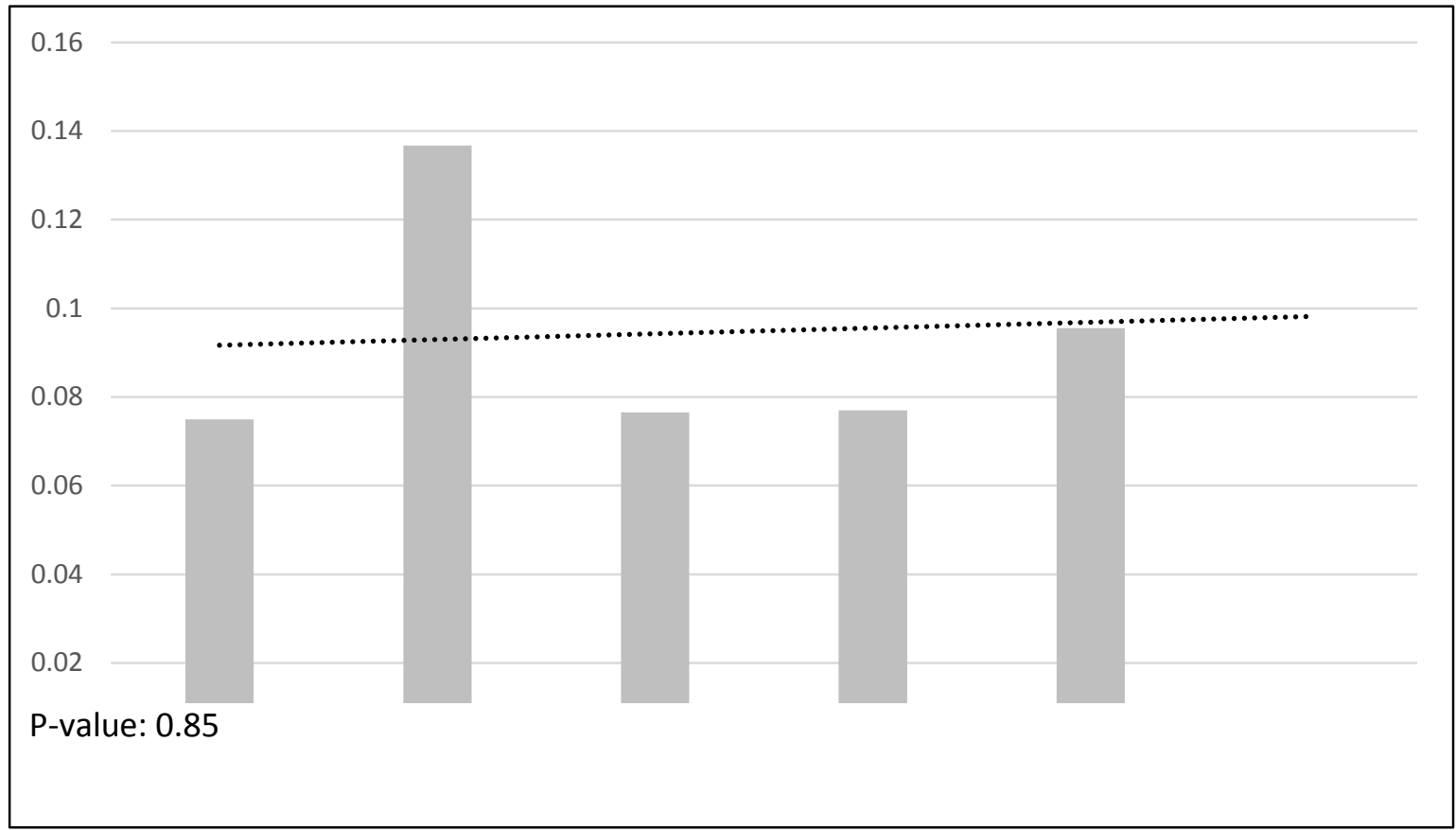

This article is protected by copyright. All rights reserved. 


\section{University Library}

\section{- M M N E R VA A gateway to Melbourne's research publications}

Minerva Access is the Institutional Repository of The University of Melbourne

Author/s:

Graudins, LV;Trubiano, JA;Zubrinich, CM;Elliott, AS;Aung, AK

Title:

Medication-related anaphylaxis treated in hospital: Agents implicated, patient outcomes, and management lessons

Date:

2018-09-01

Citation:

Graudins, L. V., Trubiano, J. A., Zubrinich, C. M., Elliott, A. S. \& Aung, A. K. (2018).

Medication-related anaphylaxis treated in hospital: Agents implicated, patient outcomes, and management lessons. PHARMACOEPIDEMIOLOGY AND DRUG SAFETY, 27 (9), pp.1029-1033. https://doi.org/10.1002/pds.4587.

Persistent Link:

http://hdl.handle.net/11343/284373 